\title{
Understanding the Function of Empathy through Laila Halaby's West of the Jordan
}

\author{
Ishak Berrebbah
}

Coventry University, United Kingdom

Arab American fiction has received great attention in the post-g/11 period. This ethnic literature has been put under a critical lens due to the aspects that shape it and the issues discussed in it. One of the main objectives of Arab American fiction is to bridge cultural differences and appeal to its readers, both Arabs and non-Arabs. This particular objective is achieved by the authors' willingness to trigger empathetic engagement with their characters. As such, this paper looks at how Laila Halaby's West of the Jordan (2003) functions in accordance with the poetics of empathy. In other words, the aim of this paper is to show how fiction appeals to its readers through empathy and how empathetic engagement sustains the characters-readers connection, taking West of the Jordan as a literary example. This paper suggests that empathy in fiction is multi-layered and serves different purposes. The arguments are based on a conceptual framework supported by scholarly perspectives of prominent critics and theorists such as Chielozona Eze, Heather Hoyt, and Suzanne Keen, to name just a few.

Keywords

Empathy; West of the Fordan; Readership; Arab American; Laila Halaby.

How cruel the world can be.

Halaby (110)

Literature invites a more intimate experience. Hoyt (415)

Laila Halaby provides a critique of, and comment on, the lives of Arab Palestinian women who live in Palestine and the USA (which generates a bicultural narrative). West of the fordan presents female characters in troubled, often tragic, situations, projecting issues related to gender discourse, patriarchy, social and political pressures, and also cultural anxieties. The portrayal of Arab 
Palestinian female characters evokes empathetic engagement and provides a strong view of the challenges that they encounter to not only fulfil their lives, but to survive. The novel tells the story of four Arab female cousins of Palestinian origin in their adolescence years. These are Soraya and Khadija who live in the USA, Hala who lives between Jordan and the USA, particularly Arizona, and Mawal who lives in a traditional Palestinian village known as Nawara. They encounter several bitter experiences due to cultural, political, social, and also economic reasons.

Halaby establishes an angle from which readers can understand and vicariously experience the feelings, thoughts, and predicaments of her female characters, creating a particular resonation emotionally and cognitively, in addition to projecting a particular type of communication between lives in the real world and lives in the fictional one. Halaby, as such, attempts to formulate a relationship between her narratives and her readership on the basis of the poetics of empathy. It is difficult to conceptualise empathy because it has inconsistent definitions (Taylor et al 2016). However, the most convenient definition that fits the scope of this paper is expressed from Barnett and Mann's perspective. They define empathy as "a cognitive and emotional understanding of another's experience, resulting in an emotional response that is congruent with a view that others are worthy of compassion and respect and have intrinsic worth" (230). This definition is applicable to the way in which readers regard characters and events in the fiction that they read. This is because literary narratives, as Mar and Oatly argue, are a reflection of real social experiences - abstracted and simulated. In other words, "stories model and abstract the human social world" (173). Suzan Keen, in her Empathy and the Novel, states that "contemporary novelists frequently connect fiction with empathy in their comments on creativity and the effect of novel reading" (121). It should be acknowledged, however, that not all readers have the same empathetic capacity when reading a literary text, particularly fiction, and that a novelist cannot maintain complete control over responses to his/her fiction. Literature, in Chielozona Eze's words, "is not about whether a particular character is likable or not; rather, it is the means through which authors interrogate the human condition" (311).

Given that West of the fordan traces the lives and experiences of Arabs inside and outside the USA, Heather Hoyt opines that Arab novelists, including Laila Halaby, in their contemporary literary productions aim at both humanising, and triggering the sense of empathy, for Arab communities amongst particularly Western readers. Hoyt thinks that, by doing this, Arab novelists construct 
a relationship with Western readers characterised by emotional understanding and bridging the gap of cultural differences:

Arab women novelists do not present their stories as "true" or the victimized voices of Arab women to be taken at face value. Instead, the empathic quality of the novelists' writing encourages Western readers to both think and feel, to see themselves in similar situations; this quality helps close the assumed distance between their Arab subjects and their Western readers without erasing the differences in culture and identity formation. (405)

The representations of Arab women in West of the Fordan, inside and outside the USA, supports Hoyt's opinion. Furthermore, Halaby's novel is regarded as an Arab story that provides "an accurate account of Arab women's lives" (Hoyt 412). This positions her, especially from a marketing perspective and for publishing purposes, as a native informant. The Arab American critic David Williams states that "although the people in Arab-American literature may be settled, and even well rooted, in the United States, they constantly make reference to personal, cultural, historical, and political realities in their families' countries of origin" (55). Being a native informant, I argue, sustains Laila Halaby's endeavours to connect with her readers and adds more credibility to her portrayal of the social and political experiences of her characters, making her narratives a genuine extension of real-world events, and also, as Salaita purports, ascribing to her novel a "realistic style" (131). Her nativity allows her readers to immerse themselves deeply in the fiction that she writes, and the possibility to trigger a sense of empathy becomes even stronger in a positive sense. In Keen's terms, "women writers very often promote the positive consequences of empathetic reading experiences, not only for women readers" (Keen 123-124). However, it is worth pointing out that the notion of "native informant" is challenging for Arab authors who are active in the West, particularly the USA, especially for women authors. This is because their Arab identities would be regarded as a second-class category and, for this, their voices are insufficiently heard by the Western audience. In my interview with the Arab American novelist Rajia Hassib, she claims that there is more emphasis on the word "Arab" when we want to know how Arab American identity is perceived and understood. This means that being a native informant can be regarded from both positive and negative perspectives. Positioning Arab American authors - including Laila Halaby - as native informants seems to have little support from David Williams. He says: 
"while many of us [Arab American authors] write (and live) with a sense of a gap between who we are and how we are perceived - and take pains to communicate across it - our vocation is to be artists, not "native informants" (63). Williams's criticism is based on his point of view that writers weave their literature to meet their reader's expectations and interests, which is not the primary purpose of literature. For him,

People read 'ethnic' literature with very limited ideas about what they will find there. What does not confirm their prejudices, support their theories, or serve as background material for an issue that interests them may be overlooked or dismissed as irrelevant. In order to have an influence on the American literary scene - or the American scene more generally - ArabAmerican literature needs to be read as literature (63).

Interestingly, David Williams's second point of view, however, clashes with Sahar Mustafah's, an Arab American writer and novelist, in terms of the purpose of writing literature. The latter, in an interview conducted with me, explains that she writes her fiction while considering her primary audience's reactions and responses. She says: "As a writer, I am always writing for my immediate community: Palestinians, Americans, and Muslim Americans. So these are the audiences who are in front of me as I am writing. When you are thinking about audience, it is easy to be worried about how something you are creating is going to be received" (2021). This means that readers' responses and expectations are important for contemporary Arab American authors, especially if their literary outputs tackle sensitive issues related to Islamophobia and terrorism.

In addition, with regards to Hoyt's research about the response of readers to fiction, particularly Arab American novels, she takes her literature students as a case study to claim that they "can learn to empathize with people from other communities rather than viewing them as objects of research" (415). Her readerresponse approach is based on how the texts are interpreted by her students after certain expectations and also their prior knowledge of the culture that the materials being read focus on; for instance, the position of Arab women in Arab culture. Hoyt, on this matter, comments: "each reading challenges us to rethink our perceptions of Arab women and to consider the ways in which U.S. media have influenced our views before reading these texts. Students need to be able to situate their understanding of American cultures as they learn about Arab cultures" (31). In this sense, Arab American fiction, including 
West of the fordan, provides new angles from which to understand and perceive things differently by Western readers overall and American readers specifically. Hoyt, furthermore, asserts that her students, through critical reflections and engagements with such ethnic novels, "developed a deeper awareness of their own cultural positioning as well as understanding the perspectives of Arab women subjects constructed in the literary works" (420). This means that a novel can engage "personalities, themes, and situations that many readers can identify with regardless of their cultural and ethnic backgrounds" (Hoyt 414). In other words, Laila Halaby in her novel West of the fordan, borrowing Hoyts's words, "conveys the complexities of her Arab American characters' lives but also provides a space for readers to make connections with their own experiences" (414). This serves the agenda of simulating readers' social experiences which is basically characterised by emotional and reflective reactions to the fiction being read. In this context, Mar and Oatly explain their understanding of literature as a simulative experience - they purport that fiction introduces "models or simulations of the social world via abstraction, simplification, and compression" (173). They also point out that literature, particularly fiction, "creates a deep and immersive simulative experience of social interactions for readers. This simulation facilitates the communication and understanding of social information and makes it more compelling, achieving a form of learning through experience" (173). This simulative experience, in effect, contributes to the development of empathetic engagement. They suggest that "engaging in the simulative experiences of fiction literature can facilitate the understanding of others who are different from ourselves and can augment our capacity for empathy and social inference" (173).

On the basis of Hoyt's study, and Mar and Oatly's argument, Laila Halaby's novel attempts to shed light on two important benchmarks throughout the relationship between narrative fiction as a simulative experience and her readership: the first one is that "consumers of literary stories experience thought and emotions congruent with the events represented by these narratives", the second one, as Mar and Oatly opine, is that stories mirror reality and situations as lived out in the social world. These two elements help to trigger empathetic engagement with characters in West of the fordan, especially female characters. They help to trigger empathy because they immerse the reader in the Arab female experience and also, as Hoyt might suggest, there's some correlation between Arab women's experiences and all women's experiences, especially when it comes to gender discourse - a global phenomenon.

This, moreover, is also because Arab women can be regarded in the Arab 
community inside or outside the USA as the most afflicted category due to the multi-faceted oppression they go through and confront; this includes racial profiling, sexist treatment, ethnic segregation, patriarchy and struggle for gender equality. Laila Halaby, for instance, shines a light on the struggle that Palestinian women go through due to the political quarrels between Palestine and Israel. Halaby turns her novel, in this regard, into serving the Palestinian case and voicing the concerns of Palestinians, particularly women. This results in affirming her nationalist stance, given that she has Palestinian roots. Mawal, the narrator in the novel, tells us what her relative Aunt Farah experiences at the Israeli checkpoint when she aims to cross the borders between Palestine and Jordan to visit her family - humiliation, self-pity, and oppression: "Farah felt nothing as she took off her clothes all the way down to naked, avoiding looking at her body whose loose flesh she rarely inspected, almost as if it belonged to someone else" (49). Mawal comments that these regular incidents "were accepted as part of life" (49). The novel portrays how Palestinian women struggle to live in the areas occupied by the Israeli regime. The incident of Farah produces negative emotions and also certain identification with particular readers who go through similar experiences, for instance Palestinian female readers ${ }^{1}$ in occupied areas, who can relate Farah's situation to their own. It is clear that the novel demonstrates the emotional state of its female characters in many scenes, given that "emotions are central to the experience of literary narrative fiction" (Mar et al. 818). This contributes to a particular type of empathetic experience. Triggering emotions throughout her fiction, I argue, Laila Halaby opts for an empathetic narrative technique.

The novel also introduces us to the socio-cultural calamities that burden women in Palestine. This is shown through the experiences of the female character Um-Lubna who has lost her family in a tragic accident: "her husband, two sons, and parents were killed when their truck exploded after being hit by another truck" (64). Her own community in Palestine, particularly in the Village of Nawara, alienates her because she acts against people's expectations. She does not follow the traditional measures of how a widowed woman should behave, i.e., she exposes her sexuality and tries to celebrate her body. She therefore receives negative attitudes and judgments and becomes otherised. She realises that her life is meaningless and that mourning the loss of her family will add only misery, without forgetting the burden of raising a mentally-ill girl who everybody looks at with repugnance. The portrayal of Um-Lubna as a hopeless/helpless widowed woman serves to deliver Halaby's idea that 
women in the Arab context are not only burdened by political issues but also socially victimised by their own communities. This idea makes readers' empathetic views towards Arab women more sustainable.

West of the fordan provides another scene that projects to the reader a negative emotion by which a particular identification might be possible. The scene concerns Hala who confronts her father's will to keep her at home in the Village of Nawara after her mother's funeral and to stop her from going back to America to finish her studies and pursue her dreams. In other words, she confronts the patriarchal treatment of her father vehemently and with strong feelings: "if I stay here, I will kill myself. I will go to my mother and then you will have the blood of two people on your hands" (45). Given that patriarchy is prevalent in mostly all cultures and societies, the experience of Hala, and also of Khadija, Mawal, and Soraya as explicated in previous sections in this paper, can project some mutuality with female readers. In this respect, the readers not only engage with the novel empathetically but also critically and analytically. These female characters are introduced by Laila Halaby as an example of Arab women who struggle in both realms: the homeland and the diaspora. She builds empathy for these particular characters over the course of West of the fordan by showcasing the calamities that they confront in various aspects of their life; either cultural, political, social, economic, or even religious. Such thorough portrayal increases the possibility of identification with particular readers. The narrator in the novel also employs certain terminologies and statements that are often associated with emotions and compassion to invite the reader to emphatically reflect. This is apparent though Mawal's statement: "you will find many women here [Palestine] grieving over sons and husbands who have forgotten them, or grieving over the evils that country [USA] has introduced their sons to, like drugs and drinking and loose women and gambling" (15). Reflecting on the meaning of her name [Joy], Aunt Farah offers a similar statement of the same context: "one whose name means joy could only know misery" (50).

The narrative techniques to evoke certain empathetic responses towards women continue by portraying domestic violence in family life. A good example of this is what happens to Khadija who has been severely rebuked by her father because of her brother's lie: "scary is the rumor started by my brother, Muhammad, whose two dollars I took to buy a barrette, that he saw me at school kissing Michael behind the gym at lunch and having baba not believe me because he doesn't have any reason to" (174). Khadija's father's 
violence is further evidenced in other scenes in narratives. It appears when he comes home drunk and beats his wife and his daughter Khadija. The latter, as a narrator, says:

I'll tell you what the scariest thing is: When he drinks. He doesn't do it that often and he doesn't have to drink that much before his eyes becomes bullets, his fists the curled hands of a boxer, and our living room the ring of Monday Night Wrestling [...] One time I went into the yard to look for a ball I had lost in the bushes the day before, and I found my father drinking. He grabbed my arm and held his bottle in front of me. 'Drink'. he said $[\ldots]$ he pulled me by the arm and then by the ear and dragged me into the kitchen where my mother was cutting vegetables. 'Oh mother of Shit', he called to her. 'Your little dog of a daughter has been drinking. Smell her mouth'. (38)

The start of this quote - Khadija's words: "I'll tell you what the scariest thing is" - aims to appeal to the readers' attention, address them, and make them absorb her tragic experiences, inviting them to evaluate her circumstances with compassion and sympathy. In his critique of West of the fordan, Steven Salaita points out that Khadija's experiences are strikingly realistic and that they "register as familiar to anybody who grew up the child of immigrants in the United States" (135). Salaita's comment is strongly valid because he himself is an Arab American individual who can relate his diasporic experiences to the characters in Halaby's novel, given that he regards himself as an avid reader of such ethnic literature, making him a good example of readership.

Along the same lines, West of the fordan depicts mostly all of its Arab Palestinian female characters in troubled situations, confirming its agenda that these characters are a prototype of many women in Arab societies who need to be empathised with. Not only this, but the novel also serves another objective, that of bringing Arab culture closer to non-Arab readers, broadening universal understanding, and reducing cultural differences, especially if empathetic engagement is successfully triggered. In addition, given that West of the fordan is post-9/11 fiction, it can be regarded as a key tool to deconstruct the discourse of "us" versus "them" through empathy and identification between readers and characters. In his $9 / 11$ Fiction, Empathy and Otherness (2015) Tim Gauthier explains that after $9 / 11$ some authors were encouraged to create "a counter-narrative to the dominant strains presented by the government and the media" (1). Such counter-narrative is characterised 
by a great sense of empathy towards characters in fiction, particularly those who are vulnerable and traumatised. Empathy in this fiction, according to Gauthier, is a significant element to establish a constructive view towards a solution to such geopolitical crisis, drawing on the language of commonality and sameness. In a similar sense, "instead of seeing the divisive nature of the event, these writers focus on its capacity to unify" (Gauthier 1). Such unity leads to a process of cosmopolitanisation. For this, Gauthier, throughout the post-9/11 fiction selected in his study, "examines the ethical and political implications revealed in the exercising or withholding of empathy" (1). He further acknowledges that "though empathy, in and of itself, may not be sufficient, it is nevertheless a vital component in the generation of actions one might identify as cosmopolitan" (1). The borderlines determining "us" from "them" may well be evaded by the capacity that the novel has to make the reader empathise with the characters who are regarded by the former as the other. In other words, a novel, in a constructive manner, contributes to the reconsidering of the process of otherisation, especially if cultural differences are identified and also minimised. A good example of this is the Arab characters in post-9/11 fiction and their relationship with white American readers, and West of the fordan can serve this equation effectively. ${ }^{2}$ This is apparent in Halaby's narrative through the attack on Walid and Soraya - two Palestinian immigrants - by white American men in The fack Knife, a bar located in the suburbs of Tucson in Arizona. The attack is triggered by ethnic bias and racial categorisation (58). The novel introduces its Arab characters in the US context as vulnerable and sufferers to their observers (readers). Such vulnerability and suffering is further projected throughout another Arab character - Haydar. He is Soraya's uncle who emigrated from Palestine to the USA following the tragic death of his father. His diasporic mediations and conditions lead him to psychological illness and mental instability. In a discussion with Soraya, Hamdi, another relative of hers, expresses how sorry he is for Haydar and the situation he ends up in:

Your uncle is like other men you see, except this one lies on his back in the middle of a city park and talks to pigeons and imitates statues. Clinically speaking he is bipolar, paranoid schizophrenic, but for real life he is crazy. Not one hundred percent crazy, but walking toward it at a rapid pace, catalysed by God knows what monster inside him. We try to help, but there is not much we can do - there is not much anyone can do. I think you needed to see him now, while you can recognize him. (214) 
The situations of male characters put them in the same pot as their female counterparts - they have troubled lives and unpleasant experiences that trigger an empathetic readership. By the same token, Halaby points in her fiction to other factors that contribute to erasing differences - particularly cultural ones - between her characters and the readers, especially American readers. This is demonstrated - in addition to vulnerability and trauma as examples of commonality as explained earlier - through the participation of Arab American characters in American life and society, their celebration of American traditions, and the American citizenship they attain, asserting themselves within a US framework. Soraya, for instance, is regarded as too American for her Arab identity and origin. She is described by her cousin Mawal as a girl "who ate too much cereal when she was young and has the foolishness of an American in her blood" (19). This projection of Americanness and the politics of sameness is not exclusive to West of the fordan only, other Arab American women authors also aim at shedding the light in their writings on the extent to which Arabs in the USA practice their Americanness, informing the readers that Arab communities are nothing except a stream that forms overall American society. By this, they demonstrate for their readers a particular suggestion that they do not undermine cultural specificity but rather enhance cultural harmony and integration. A good example of such authors, to name just a few, are Diana Abu-Jaber and Saha Mustafa. The latter for instance, in her The Beauty of your Face (2020), shows how her characters celebrate Thanksgiving (62) and Halloween (58) - two major American traditions. In my interview with Mustafah Sahar, she gives a statement on how such celebrations lead to integration. She says: "for me, I would say that these were, for my family in particular, attempted efforts to make us feel the same as our white counterparts [in the USA] and not really anything more than that" (2021).

In addition, the context of vulnerability, as explained earlier, is also apparent in the diasporic experiences of another Arab character, Dahlia. She mourns her troubled life in the USA and laments her socio-economic conditions after she finds out that her children might have been kidnapped and she does not have the means to either protect them or support them: "To come this far only to be poorer than you were when you started poor and then to have your children stolen is more than is worth enduring" (111). Drawing on such examples, a reader's response to such characters' unfortunate experiences - that of Khadija, Um-Lubna, Dahlia, Walid, and Haydar - can be evoked by certain cosmopolitan sentiments which James Brasett ${ }^{3}$ names 
as empathy, sympathy, and compassion (Gauthier 2). Of these sentiments, as Gauthier asserts, "a greater degree of emphasis has been placed on empathy, in part because it requires an active engagement on the part of the empathiser, but also because the intimations of inequality between observer and sufferer are far less strong" (2). Portraying her characters in this way to appeal to her readers' empathy is a mechanism by which Laila Halaby aims to provide counter-narratives and build a sense of cosmopolitan identification that, on the one hand, diminishes the gap between "us" and "them", and on the other hand, circumvents the discourse of otherisation in the context of post-9/11. A key aspect of this counter-narrative is triggering themes such as trauma, loss, vulnerability, and victimisation to set up that connection particularly with her American readers because the latter have experienced similar feelings and experiences as an outcome of the events of $9 / 11$. Building on Judith Butler's work ${ }^{4}$, Tim Gauthier states that "the victims of $9 / 11$ should make us aware of the 'precarious life of the other' $[. .$.$] The attacks created conditions of similarity$ that might now enable Americans to sympathetically identify with the many suffering others previously beyond their scope of consideration. After all, one is more likely to empathize with someone with whom one shares similarities" (4). Such adherence to the logic of identification through sentiment, links West of the fordan to the notion of "humanitarian empathy", given that the novel sketches the calamities that immigrants and exiled characters confront characters such as Walid and Haydar who experience ethnic prejudice and mental issues in the US diaspora.

Empathy, moreover, can also be regarded as part of Laila Halaby's feminist agenda in West of the fordan, given that the narratives are mostly centred on gender discourse and themes related to Arab women's issues and also factors of their suffering such as patriarchy, sexism, and domestic violence. In this sense, empathy can possibly be defined as "the imaginative reconstruction of the experience of the sufferer" (Nussbaum 327), particularly by female readers when the characters are women. As pointed out before, the novel focuses on the stories of female protagonists, i.e., Hala, Soraya, Mawal, and Khadija and also their female relatives both in the USA and Palestine. Laila Halaby, in an interview I conducted with her, draws attention to the link between feminism and empathy. She says: "if you empathize with my women characters there is an element of feminism within you, right. So from my standpoint that would be how I approach it" (Interview with Laila Halaby 2021). Her words might be interpreted to signal her gendering of the politics of empathy. In other 
words, her fiction serves the feminisation of empathy, directing empathetic engagement with her female protagonists - a demonstration of feminist empathy.

Chielozona Eze, in his analysis of empathy in contemporary African women's fiction, defines feminist empathy as "the ability to feel oneself into the experience of a woman in undeserved suffering. It comes to fruition when we switch perspective with a woman experiencing unfairness, injustice, or oppression because of her gender. That is, she suffers because of the position to which society has forced her body" (311). Eze's thought, in relation to what West of the fordan suggests, is applicable to how Arab female characters are positioned and treated in their society either in Palestine or the US diaspora. Feminist empathy throughout fiction, moreover, contributes to the functioning of the Arab and Arab American feminisms, and it can be regarded as a strategy to serve the needs of such ethnic feminisms effectively, given that such literature, i.e., Arab American literature, has reached great prominence in the last few decades and caught the attention of a wider audience (Salaita 2011; FaddaConrey 2014). In fact, most novels written by Arab American women authors are centred on female protagonists, namely Khadra in Mohja Kahf's The Girl in the Tangerine Scarf, Sirine in Diana Abu-Jaber's Crescent, Afaf in Sahar Mustapha's The Beauty of Your Face, Gameela in Rajia Hassib's A Pure Heart and many other examples. The problematised portrayal of Arab women in such novels, particularly West of the fordan, is transformed from weakness into a useful and powerful tactic/mechanism. This usefulness appears throughout the connection that these authors aim to build with their readers in terms of empathetic engagement. In this context, Mustafah Sahar, in an interview conducted with me says: "When we share stories we just tend to get closer and we are very voluntarily going on this journey with these characters and that's a beautiful thing. I think, inevitably, we are going to feel empathy. I think, even writing is an act of empathy, so even myself as a fiction writer I had to be in a place of empathy [...] Empathy is absolutely necessary to break down barriers" (2021). However, Arab American women authors with a feminist agenda, such as Laila Halaby, borrowing Susan Muaddi Darraj's words, "are in the precarious position of having to critique their culture while making sure not to fall into a politically charged stereotype" (248). This means that, within the context of this section, empathy should be triggered by the portrayal of Arab women in their societies while carefully avoiding the possibility that a reader might embrace the existing misrepresentations of Arab women as a marker of oppression, exoticism, and submission. 
Feminist empathy, moreover, can be regarded as a form of advocacy, given that Laila Halaby uses her fiction to echo Arab women's issues and concerns throughout her female characters. West of the fordan positions her as an authorial figure who knows well the pragmatics and systematic structure of Arab society, taking into account that Halaby has Arab Jordanian and Palestinian origin. Nina Mickwitz points out that advocacy "suggests speaking on behalf of or in solidarity with someone who is not able to speak for themselves; advocacy, is motivated by an ethical response, and is, presumably, intended to support or effect social change" (459). Advocacy not only stems from feminist issues, but also from political, social, and economic ones, and Arab American authors are concerned about it for Arabs in the USA as much as they are for those in their homelands. The Arab American cultural critic Lisa Suhair Majaj, in this context, points out that an important function of Arab American fiction, particularly through the novel as a medium of communication, is to deliver facts and emotions:

We need to write texts - especially novels - that will translate political realities into human terms, and that will create a space for empathy on the part of readers who might otherwise remain indifferent. Given the depth of ignorance and misinformation about the Arab world, we are particularly in need of prose - of writing that is capacious enough in form to convey fact as well as emotion. We need historically-grounded novels that will narrate Arab realities to American readers without sacrificing literary quality to didacticism, that will tell a compelling but also informative story. But in taking on such projects, we need to make sure that we're not writing tracts, but are writing literature. $(76)$

Laila Halaby's West of the Fordan thus not only responds to Darraj's suggestion to narrate Arab realities to American readers, but it also positions itself as a literary project that functions to narrow the gap between the two sociopolitical and cultural mainstreams, i.e., Arab and American. Despite the helpful role that empathic engagement plays in sustaining this aim -narrowing the gap - it should be worth pointing out that empathy may be impotent and cause a deconstructive effect and a potential malfunction. In his book The Dark Sides of Empathy (2019), Fritz Breithaupt suggests that empathy can be triggered just temporarily and for a short period of time. This, according to him, includes reading fiction and a characters-readers connection. After finishing the fiction being read, a reader would withdraw his/her empathy. 
Breithaupt in this respect further comments: "fiction provides another example of our preference for time-limited empathy. Most people are prepared to step into the shoes of a fictional character for a short time, even if that character undergoes the most terrible sufferings. Why is this? Because works of fiction (and narrative in general), have an ending, at which point we can withdraw our empathy" (92). On the basis of such statement, characters in West of the fordan, whether males or females, and their experiences, might have a mere temporary effect on the readers, and thus Laila Halaby's agenda might not be that successful. In a similar context, Suzan Keen, in relation to the novelreading experience, lists her critical observations that fall in line with Fritz Breithaupt's argument. On the variability of response to potentially empathic fiction, Keen purports that empathetic engagement might entail inaccuracies and passivity: "empathy with characters doesn't always occur as a result of reading an emotionally evocative fiction [...] The capacity of novels to invoke readers' empathy may change over time [...] Empathy for a fictional character need not correspond with what the author appears to set up or invite" (136). Keen also emphasises the fact that identification may include empathy, but empathy does not require identification. In other words, it is true that "character identification often invites empathy, even when the fictional character and reader differ from each other in all sorts of practical and obvious ways, but empathy for fictional characters appears to require only minimal elements of identity, situation, and feeling, not necessarily complex or realistic characterization" (xii). Regardless of this, West of the fordan remains an Arab American literary example that introduces the Arab community with its aspects to international readers, making such ethnic community more recognizable.

To conclude, Laila Halaby's West of the fordan aims to introduce Arab communities to universal/global readers, particularly Americans. The feasibility of this aim projects its strength throughout the poetics of empathy and their impact on readers' engagement with the fiction being read, especially if the process of identification is well triggered. This paper has shown that empathy has a multi-layered function: to instigate a feminist agenda; to demonstrate advocacy for vulnerable communities; to bridge cultural gaps, and also to echo humanitarian sentiments and cosmopolitan unity. In addition to this, empathy also determines, to some extent, the quality of readership and how readers respond to the author's narratives and stories, especially if these stories are a reflection of reality and a simulation of existing socio-political experiences and world events. 5 


\section{Endnotes}

1. Palestinian female readers are part of the wider audience who engage empathetically with fiction, particularly Arab American fiction. I narrowed the scope to Palestinian female readers because the identification with Palestinian female characters' experiences in West of the fordan may be stronger, and thus empathetic engagement and response to Laila Halaby's can be triggered to a large extent. I would like to point out, in this context, that in my interview with Rajia Hassib, an Arab American novelist, she explains that responses to her fiction come mostly from young Muslim women readers from different parts of the world because the latter strongly identify themselves with her characters, i.e., female characters particularly.

2. In her "New Directions: Arab American Writing at Century's End" (1999) Lisa Suhair Majaj emphasises that Arab American writers today "inhabit multiple cultures and write for multiple audiences: American, Aran, Arab American" (67).

3. For more reading about cosmopolitan sentiments please see his "Cosmopolitan Sentiments after 9/11? Trauma and the Politics of Vulnerability" (2010).

4. Judith Butler opines that "to be injured means that one has the chance to reflect upon injury, to find out the mechanisms of its distribution, to find out who else suffers from preamble borders, unexpected violence, dispossession, and fear, and in what ways" (qtd in Gauthier 4).

5. For more readings about how reality functions in fiction please consult Lars Ole Sauerberg's Fact into Fiction: Documentary Realism in the Contemporary Novel (1991).

Works Cited

Barnett, G. Mann, R. E. "Empathy Deficits and Sexual Offending: A Model to Obstacles to Empathy." Aggression and Violent Behavior, 18 (2013): 228-239. Breithaupt, Fritz. The Dark Sides of Empathy. Trans, by Andrew B. Hamilton. Ithaca: Cornell University Press, 2019.

Darraj, Susan, Muaddi. "Personal and Political: The Dynamics of Arab American Feminism." Arab and Arab American Feminisms: Gender, Violence, and Belonging. Ed. Rabab Abdulhadi, Evelyn Alsultany, and Nadine Naber. 2015, 248-261. New York: Syracuse University Press.

Eze, Chielozona. "Feminist Empathy: Unsettling African Cultural Norms in The Secret Lives of Baba Segi's Wives." African Studies. 74.3 (2015): $310-326$.

Fadda-Conrey, Carol. Contemporary Arab-American Literature: Transnational Reconfigurations of Citizenship and Belonging. New York: New York University Press, 2014.

Gauthier, Tim, S. g/11 Fiction, Empathy, and Otherness. Lanham, Maryland: Lexington Books, 2015.

Halaby, Layla. West of the Fordan. Boston: Beacon Press, 2003. 
Hoyt, Heather, M. "Teaching from Cover to Cover: Arab Women's Novels in the Classroom." The Edinburgh Companion to the Arab Novel in English. Ed. Nouri Gana. 2012, 405-423. Edinburgh: Edinburgh University Press.

Keen, Suzanne. Empathy and the Novel. Oxford: Oxford University Press, 2007.

Majaj, Lisa, Suhair. "New Directions: Arab-American Writing at Century's End." Post-Gibran Anthology of New Arab American Writing, 1999. 67-77. Ed. Khaled Mattawa and Munir Akash. Syracuse: Syracuse University Press.

Mar, R. A., Oatly, K. "The Function of Fiction is the Abstraction and Simulation of Social Experience." Perspectives on Psychological Science. 3.3(2008): 173192.

Mar, Raymond. Djikic, Maja. Oatley, Keith. Mullin, Justin. "Emotion and Narrative Fiction: Interactive Influences before, during, and after reading." Cognition and Emotion. 25·5(2011): 818-838.

Mickwitz, Nina. "Introduction: Discursive Contexts, "Voice", and Empathy in Graphic Life Narratives of Migration and Exile." Auto/Biography Studies. 35.2(2020): 459-465.

Mustafah, Sahar. The Beauty of Your Face. London: W.W. Norton Ltd. 2020.

Nassbaum, Martha. Upheavals of Thought: The Intelligence of Emotions. Cambridge: Cambridge University Press, 2001.

Salaita, Sterven. Modern Arab American Fiction. New York: Syracuse University Press, 2011.

Taylor, L. Cuff, B. Brown, S. Howat, D. "Empathy: A Review of the Concept." Emotion Review. 8.2(2016): 144-153.

Williams, David. "This Hyphen Called my Spinal Cord: Arab-American Literature at the Beginning of the 21st Century." World Literature Today. $81(1) \cdot 5^{8-63} \cdot 2007$.

ISHAK BERREBBAH is a Doctoral Researcher and graduate teaching assistant at Coventry University, UK. His research project investigates the poetics and politics of identity in Arab American fiction in the context of post9/11. He was awarded a fully-funded scholarship in 2016 to pursue a Ph.D. degree in the United Kingdom. He has published in the field of English Literature and presented many papers at renowned international conferences in various countries, but mainly the UK. His research interests intersect Diaspora Studies, Postcolonial Literature, and Arab Literature in English. berrebbi@uni.coventry.ac.uk 